\title{
Effects of COVID-19 lockdown on a bariatric surgery waiting list cohort and its influence in surgical risk perception
}

\author{
Marc Beisani ${ }^{1} \cdot$ Ramon Vilallonga ${ }^{1}$ (D) $\cdot$ Carlos Petrola ${ }^{2}$ - Asunción Acosta ${ }^{3} \cdot$ José Antonio Casimiro Pérez $^{3}$. \\ Amador García Ruiz de Gordejuela ${ }^{1}$ - Carlos Fernández Quesada ${ }^{3}$ - Oscar Gonzalez ${ }^{1}$ - Arturo Cirera de Tudela ${ }^{2}$. \\ Enric Caubet ${ }^{1} \cdot$ Manel Armengol $^{2} \cdot$ José Manuel Fort $^{1}$
}

Received: 27 July 2020 / Accepted: 17 November 2020 / Published online: 26 November 2020

(C) Springer-Verlag GmbH Germany, part of Springer Nature 2020

\begin{abstract}
Purpose The COVID-19 outbreak has forced a 2-month lockdown (LD) in Spain. We aimed to assess how that had affected our cohort of bariatric patients waiting for surgery.

Methods A review of electronic records and a structured phone interview with each patient were conducted. Changes in severity of obesity were analyzed using the Obesity Surgery Score (OSS) and changes in health-related quality of life (HRQoL) using the validated EQ-5D questionnaire. Other miscellaneous questions about behavior modifications and surgical risk perception were also analyzed.

Results All 51 patients fully answered the questionnaires. Mean age was 47 years and mean time on waiting list 91 days. Mean BMI increased during LD (42.7 vs 43.2; $p<0.001)$. Both OSS $(2.84$ vs $3 ; p=0.011)$ and EQ-5D (69 vs $64 ; p<0.001)$ mildly worsened during LD, mainly due to psychosocial issues. Twenty-seven patients (53\%) thought that perioperative risks were higher under the current circumstances but they were as willing to undergo surgery as those who believed that the risks had not increased ( $74 \%$ vs $87 \%, p=0.2)$.

Conclusions COVID-19 LD had a significant but mild effect on our cohort of bariatric surgery waiting list patients. Although perioperative risk perception had increased, patients were still willing to undergo their planned surgeries.
\end{abstract}

Keywords Obesity $\cdot$ Bariatric surgery $\cdot$ COVID- $19 \cdot \mathrm{HRQoL} \cdot$ Waiting list

\section{Introduction}

The COVID-19 outbreak continues to severely stress healthcare systems around the world, and the future implications of this pandemic, including medical activities, remain unclear for the moment. So far, it has prompted extraordinary

Ramon Vilallonga

vilallongapuy@hotmail.com

1 Endocrine, Metabolic and Bariatric Unit, Vall d'Hebron University Hospital, Universitat Autònoma de Barcelona, Center of Excellence for the EAC-BC, Passeig de la Vall d'Hebron 119-129, 08035 Barcelona, Spain

2 General Surgery Department, Vall d'Hebron University Hospital, Universitat Autònoma de Barcelona, Barcelona, Spain

3 Servicio de Cirugía General y del Aparato Digestivo, Hospital Universitario de Gran Canaria Doctor Negrín, Las Palmas de Gran Canaria, Las Palmas, Spain social measures. In Spain, a lockdown (LD) was enforced for two months, and, during that time, only those with essential occupations were allowed to leave home. Moreover, as in many other countries, health centers were reorganized, and most activities, including all non-urgent surgeries, were delayed $[1,2]$.

Bariatric surgery was not an exception, and, in accordance with the recommendation of the International Federation for the Surgery of Obesity [3], our institution's bariatric program was halted [4]. Nevertheless, deferring the treatment of obese patients, specially under LD conditions, may have had undesirable consequences. Lifestyle adjustments, mobility restrictions, and insecurity about the future could have caused an increase of body weight and the worsening of associated comorbidities, as well as a lowering of health-related quality of life (HRQoL) [5-9].

Later on, as the COVID-19 pandemic passed its first peak, guides for a safely reintroduction of bariatric surgery were being issued $[10,11]$. It was admitted that the threads of 
exposing vulnerable patients to infection were hard to balance with the consequences of leaving obesity unattended [11]. To date, a lot of questions regarding the impact of COVID-19 social measures in patients with obesity remain unanswered. Moreover, we believe that it is important to introduce the opinion of our patients to this conversation, as they are the ones effectively taking the risks [12-15].

Thus, the aim of this study was twofold: on the one hand, to analyze the effects of COVID-19 LD on our cohort of bariatric surgery waiting list patients in terms of obesity severity and HRQoL, and on the other, to assess their surgical risk perception and willingness to receive their planned surgery under the current uncertain situation.

\section{Patients and methods}

A descriptive cohort study was performed including all patients enrolled in the bariatric surgery waiting list of our institution, a tertiary referral center, before the LD was declared in Spain on March 14, 2020. These patients had already completed the preoperative study and had been reviewed and approved for surgery by a multidisciplinary board. Patients waiting for a revisional surgery were also included. This study was approved by the Ethics Committee of our institution (dossier number 359/2020).

The effect of LD on the severity of obesity was evaluated through changes in the Obesity Surgery Score (OSS) [16]. OSS is an index composed by three items (weight, obesityrelated comorbidities, and socio-labor impact of obesity), each stratified according to severity that produces a final score that ranges from 0 (best) to 8 (worst) points, summarized in three grades (A, 0-2 points; B, 3-5; C, 6-8) (Table 1). HRQoL before and after LD was analyzed with the Spanish validated version of the EQ-5D questionnaire, a health status measure tool developed by the international research group EuroQol $[17,18]$. EQ-5D assesses 5 different dimensions (mobility, self-care, usual activities, pain/discomfort, and anxiety/depression) with a very simple 3 -point scale (from 1 , best, to 3 , worst) and also summarizes the general health status with a self-rated index (from 0, worst, to 100, best) (Table 2).

All data used in this study was obtained during May 5 and 10, 2020, when a progressive lifting of LD had been already announced but still not implemented. For each patient, both our institution's electronic clinical record and the national centralized electronic database, which contains primary care and other medical institutions' reports, as well as a log of current and passed drug prescriptions, were reviewed. Afterwards, all patients were contacted by phone by three of the authors (RV, CP, and AC) and asked to answer to a structured questionnaire of 40 short items. It included retrospective "before LD" OSS and EQ-5D evaluations, current "after LD" OSS and EQ-5D evaluations, and a number of miscellaneous questions about behavioral changes during LD, along with surgical risk perception and prioritization preferences. In case of disparity between the previously collected clinical data and the answers of the patients (e.g., medication still present in electronic records that the patient had stopped long before), the item was further discussed until a clarification was reached. Data was shared and analyzed by all authors through e-mail and structured video meetings.

For quantitative data, normality was explored with the Shapiro-Wilk test. Normal quantitative data was analyzed with the Student's $t$ test for paired data. Otherwise, the nonparametric Chi-square test and Wilcoxon signed-rank test for paired data were used. All statistical tests were two-sided, and a $p$ value $<0.05$ was considered significant. Statistical analysis was performed with SPSS v20 (SPSS Inc., Chicago, IL, USA) and figures designed with Datagraph v4.5.1 (Visual Data Tools Inc., North Carolina, USA).

\section{Results}

There were 51 patients in the bariatric surgery waiting list of our institution before LD was enforced, 31 (61\%) expecting a primary surgery and $20(39 \%)$ a revisional surgery, mainly due to insufficient weight loss or reflux. The mean age was $47( \pm 10)$ years, and there were $33(65 \%)$ females. The mean time on the waiting list was $91( \pm 30)$ days. All patients fully answered the structured questionnaire, requiring around 8-10 min per patient, and all of them were satisfied with the call. None had been hospitalized during LD nor diagnosed with COVID-19.

There was a mild but statistically significant increase in body mass index (BMI) during LD (42.7 vs $43.2 \mathrm{Kg} / \mathrm{m}^{2} ; p<$ $0.001)$, in line with a strong decline of patients following any weight-loss program (45\% vs 20\%; $p<0.001$ ) (Table 3 ). Besides, 25 patients (49\%) referred having changed their diet, $21(41 \%)$ having had more frequent sleep disorders, and 15 $(29 \%)$ a lower than usual self-esteem (Fig. 1).

Regarding changes in OSS before and after LD, only the socio-labor aspect seemed to have worsened significantly ( 0.30 vs $0.42 ; p=0.014)$. However, a slight but significant increase in the total score was observed (2.84 vs $3 ; p=0.011)$, which corresponded with 4 patients $(8 \%)$ escalating from grade A to grade B (Fig. 2). HRQoL questionnaire EQ-5D also showed a higher level of anxiety after LD (1.2 vs $1.5 ; p$ $=0.001)$ and a decreased self-rated health index (69 vs $64, p<$ 0.001) (Fig. 3).

A majority of patients (84\%) were worried about a possible delay on their planned surgery (Fig. 1). Perioperative risks were believed to be higher than before the COVID-19 outbreak by 27 patients (53\%). However, these subjects were similarly willing to undergo their surgery than those who believed that the risks had not increased $(74 \%$ vs $87 \%, p=0.2)$ 
Table 1 Obesity Surgery Score (OSS)

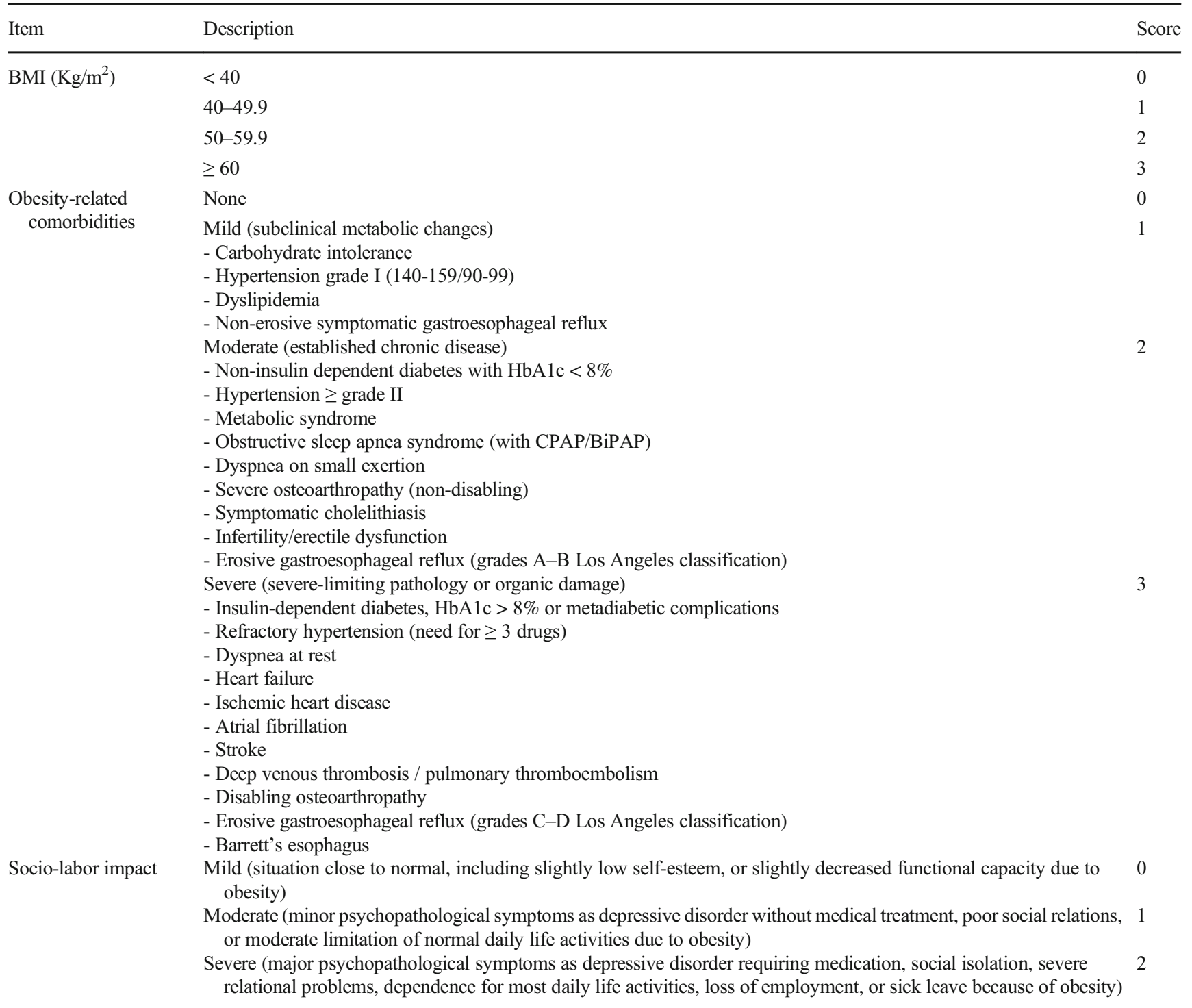

The final OSS, ranging from 0 to 8 , is obtained by adding the scores of the three independent items. It may be further simplified in 3 grades: A (0-2), B (3-5), and C (6-8). BMI body mass index, CPAP/BiPAP continuous positive airway pressure devices

(Fig. 4). Overall, they thought that severity should be the main prioritization criterion.

\section{Discussion}

This descriptive study aimed to explore the effects of COVID-19 LD on the cohort of patients waiting for a bariatric surgery in our institution. To that end, exhaustive reviews of electronic clinical records and structured phone interviews were conducted. We found an increase in BMI and a decline in weight-loss program compliance during LD. Moreover, both OSS and EQ-5D scores worsened during LD, although changes seemed to be more related with social and psychological issues rather than organic deterioration. Around half of our patients believed that perioperative risks had increased in the aftermath of COVID-19 LD, but their willingness to undergo their planned surgery was still very high and not significantly different than among those who believed that the risk remained equal than before COVID-19.

Obesity is a chronic illness with progressive deleterious effects on many fronts, so, in order to grasp the severity of its impact on a particular patient, it is important to take into account the level of organic damage induced by the associated comorbidities and also its social repercussions. A number of systems have been proposed to integrate all these aspects, being the Edmonton Obesity Staging 
Table 2 Quality of life EQ-5D questionnaire

Item Score

1. Mobility

- I have no problems in walking about

1

- I have some problems in walking about

- I am confined to bed

2. Self-Care

- I have no problems with self-care

- I have some problems washing or dressing myself

- I am unable to wash or dress myself

3. Usual activities

- I have no problems with performing my usual activities

- I have some problems with performing my usual activities

- I am unable to perform my usual activities

4. Pain/discomfort

- I have no pain or discomfort

- I have moderate pain or discomfort

- I have extreme pain or discomfort

5. Anxiety/depression

- I am not anxious or depressed

- I am moderately anxious or depressed

- I am extremely anxious or depressed

System (EOSS) [19-23] and the King's Obesity Staging Criteria (KOSC) $[24,25]$ the most commonly used. For this study, however, OSS [16] was preferred. It provides an objective and simple categorizing frame, and, unlike
EOSS, weight, comorbidities, and psychopathological consequences of obesity are independently assessed. Moreover, these three items generate a single numeric score and a graded scale, which makes comparisons easier than with KOSC.

Although BMI significantly increased during LD, changes seemed to be too small to reflect on OSS. No relevant worsening of comorbidities was found either. This is likely due to a relatively short lapse of time for chronic diseases like hypertension or diabetes to aggravate, but the fact that patients have had a limited access to medical consultations, and therefore to reevaluation, may also be involved. OSS socio-labor status, however, did show a deterioration during LD. Moreover, the validated HRQoL questionnaire EQ-5D also showed a selective increase in the anxiety/depression item. These results are in accordance with the other two published studies about the impact of COVID-19 pandemic on bariatric patients [26, 27]. Two weeks after the stay-at-home order was issued in Texas (USA), Almandoz et al. [26] asked a local cohort of operated and non-operated obese patients about lifestyle and sociolabor topics, reporting that around three quarters of them had anxiety or depression issues. Likewise, Walędziak et al. [27] conducted a similar inquiry on a Polish population, finding the same results.

The mean waiting time of 3 months may not seem much for half of our cohort to be worried about a delay on their surgery. However, it does not include the previous endocrinological evaluation and subsequent preoperative study. Unfortunately, the whole process can take a few years in our public institution. Given that waiting for
Table 3 Changes in obesityrelated items and quality of life during COVID-19 LD

\begin{tabular}{llll}
\hline & Before LD $(n=51)$ & After LD $(n=51)$ & $p$ Value \\
\hline BMI $\left(\mathrm{Kg} / \mathrm{m}^{2}\right)$ & $42.7( \pm 10)$ & $43.2( \pm 11)$ & $<0.001^{*}$ \\
Following any weight-loss program & $23(45 \%)$ & $10(20 \%)$ & $<0.001^{*}$ \\
Number of drugs used & $6.1( \pm 4)$ & $6.1( \pm 4)$ & 1 \\
OSS & & & 0.6 \\
- BMI & $0.86( \pm 0.9)$ & $0.88( \pm 0.9)$ & 0.3 \\
- Obesity-related comorbidities & $1.68( \pm 1.1)$ & $1.70( \pm 1.1)$ & $0.014^{*}$ \\
- Obesity-related socio-labor impact & $0.30( \pm 0.5)$ & $0.42( \pm 0.6)$ & $0.011^{*}$ \\
- Total score & $2.84( \pm 1.7)$ & $3.00( \pm 1.8)$ & 0.6 \\
EQ-5D & & & 1 \\
- Mobility & $1.29( \pm 0.5)$ & $1.31( \pm 0.5)$ & 1 \\
- Self-care & $1.2( \pm 0.4)$ & $1.2( \pm 0.4)$ & $1.2( \pm 0.4)$ \\
- Usual activities & $1.2( \pm 0.4)$ & $1.4( \pm 0.6)$ & 0.2 \\
- Pain/discomfort & $1.5( \pm 0.6)$ & $1.5( \pm 0.7)$ & $0.001^{*}$ \\
- Anxiety/depression & $1.2( \pm 0.5)$ & $64( \pm 1.8)$ & $<0.001^{*}$ \\
- Self-rated health index & $69( \pm 1.8)$ & & \\
\hline
\end{tabular}

Data is shown as mean ( \pm standard deviation) or $n$ (percentage)

$L D$ lockdown, $B M I$ body mass index, OSS Obesity Surgery Score, $E Q-5 D$ EuroQol group quality of life validated questionnaire. *Statistically significant differences 
BEHAVIORAL CHANGES DURING COVID-19 LOCKDOWN

Have you been exercising regularly?

Have you changed your diet?

Have you had more frequent nightmares or sleep disorders?

Has the current situation lowered your self-esteem?

Has your sexual desire been modified during lockdown?

RISK PERCEPTION AND PRIORITIZATION PREFERENCES

Do you think that perioperative risks are higher right now?

Are you worried about a delay on your planned surgery?

Under the current circumstances, would you undergo your planned surgery?

Under the current circumstances, should patients be prioritized by severity?

Under regular circumstances, should patients be prioritized by severity?
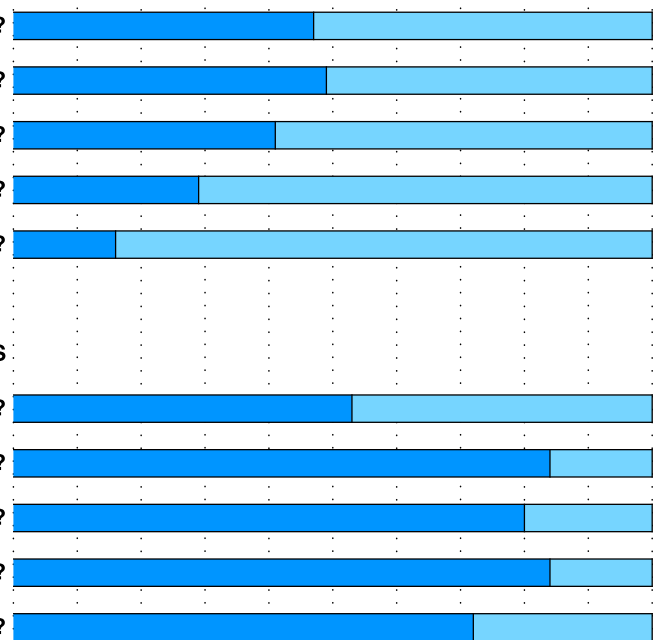

Fig. 1 Answers to miscellaneous questions about behavioral changes, surgical risk perception, and prioritization preferences by our bariatric surgery waiting list cohort $(n=51)$

a bariatric surgery is associated with a decreased HRQoL and an increased metabolic risk, including death [5-7, 28], it is understandable that even believing that perioperative risks had increased under the current circumstances, the vast majority of patients were still willing to

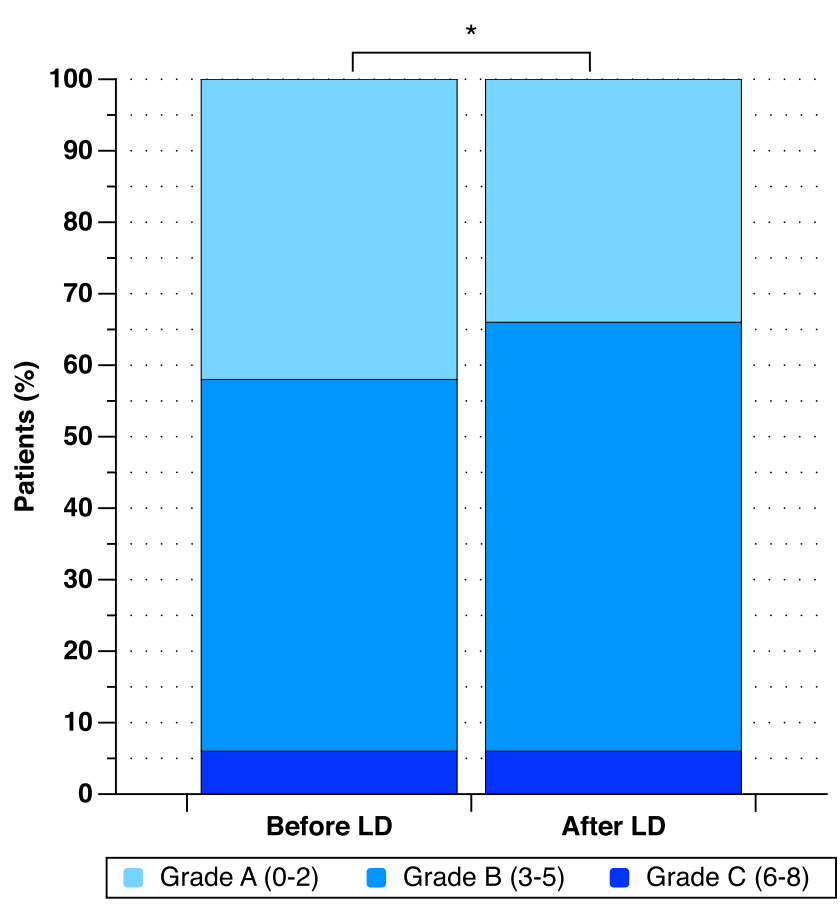

Fig. 2 Changes in Obesity Surgery Score grade on our bariatric surgery waiting list cohort $(n=51)$ before and after COVID-19 lockdown (LD). $* p=0.046$ undergo immediate surgery. This point should be noticed by health administrators when planning the reintroduction of regular activities, in order not to overlook old known pandemics for the sake of the new. Furthermore, involving the patients' opinions in decision-making processes not only has a positive effect on patient-physician communication but also has been reported to improve clinical outcomes $[12,13]$. In this regard, telemedicine is a very exciting tool. Maybe to date, no definitive advantage over conventional outpatient consultation has been found in the management of bariatric patients [29-31], but COVID-19 has shown us that we must be ready to rethink "conventional" and adopt and develop new ways to keep in touch with our patients.

This work has several limitations worth mentioning. First of all, our results are based on a mixed cohort of patients waiting for primary and revisional surgeries, which may have different baseline situations and expectations about the forthcoming surgery. Secondly, the baseline OSS and EQ-5D outcomes were obtained retrospectively, as these scores were not routinely recorded. Besides, they were partially based on self-reported data. Finally, the lack of a control group makes it difficult to ascertain if the reported effects of COVID-19 LD are specific to the bariatric patients or, instead, equal to that experienced by the general population. Nevertheless, we believe that the results of this study offer some interesting insights and contribute to a more meaningful conversation about how to manage bariatric surgery programs under the influence of COVID-19. 
Fig. 3 Changes in quality of life (EQ-5D) on our bariatric surgery waiting list cohort $(n=51)$ before and after COVID-19 lockdown (LD). $* p=0.001, * * p<0.001$.

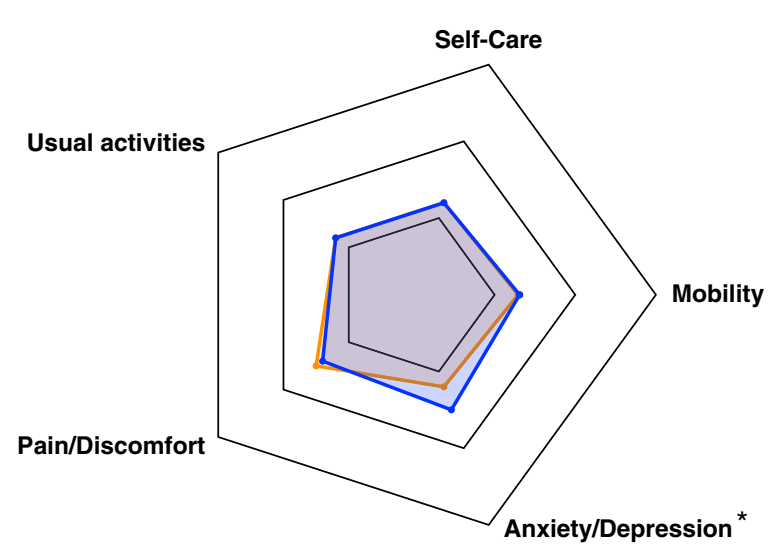

Health Index

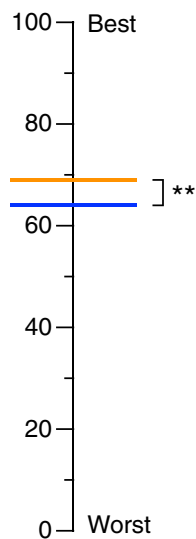

\section{Conclusions}

In summary, COVID-19 LD had a significant but mild effect on our cohort of bariatric surgery waiting list patients. Both OSS severity index and EQ-5D quality of life outcomes were slightly worse after LD, mainly due to socio-labor and anxiety-related problems. Although perioperative risk perception had increased,

patients were still willing to undergo their planned surgeries.

Authors' contributions Study conception and design: RV, AA, JC, CF, $\mathrm{CP}$, and $\mathrm{MB}$

Acquisition of data: $\mathrm{RV}, \mathrm{CP}$, and $\mathrm{AC}$

Analysis and interpretation of data: All authors

Drafting of manuscript: $\mathrm{MB}, \mathrm{RV}$, and AA

Critical revision of manuscript: All authors

Data availability All used data is available at our institution.

\section{Compliance with ethical standards}

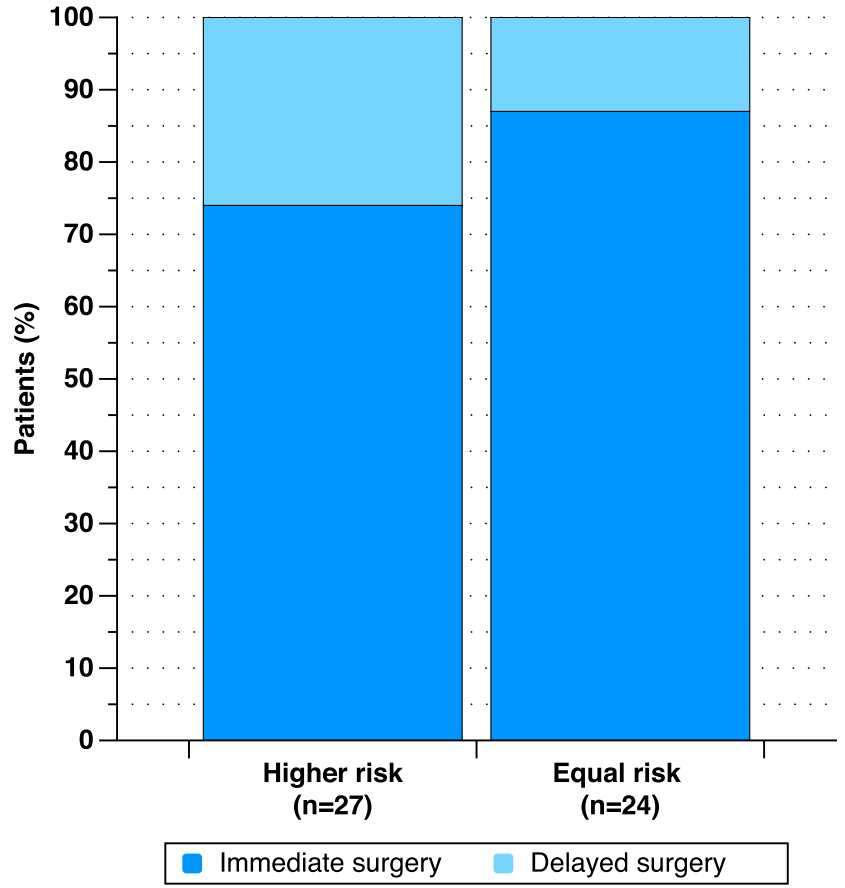

Fig. 4 Willingness to undergo immediate surgery according to the group of perceived perioperative risk after COVID-19 outbreak $(p=0.2)$
Conflict of interest The authors declare that they have no conflict of interests.

Ethics approval All procedures performed in studies involving human participants were in accordance with the ethical standards of the institutional and/or national research committee and with the 1964 Helsinki declaration and its later amendments or comparable ethical standards. This retrospective study was approved by the Ethics Committee of our Institution (dossier number 359/2020).

Consent to Participate and Consent for Publication At inclusion in the waiting list, all patients gave their consent for the anonymized use of their medical data.

Code availability Not applicable.

\section{References}

1. Brethauer SA, Poulose BK, Needleman BJ, Sims C, Arnold M, Washburn K et al (2020) Redesigning a department of surgery during the COVID-19 Pandemic. J Gastrointest Surg. https://doi. org/10.1007/s11605-020-04608-4 
2. Torzilli G, Vigano L, Galvanin J, Castoro C, Quagliuolo V, Spinelli A et al (2020) A snapshot of elective oncological surgery in Italy during COVID-19 emergency: pearls, pitfalls, and perspectives. Ann Surg. https://doi.org/10.1097/SLA.0000000000004081

3. Yang W, Wang C, Shikora S, Kow L (2020) Recommendations for metabolic and bariatric surgery during the COVID-19 pandemic from IFSO. Obes Surg 30(6):2071-2073. https://doi.org/10.1007/ s11695-020-04578-1

4. Sanchez-Cordero S, Vilallonga R, Rangarajan M, Rodríguez-Luna MR, Beisani M, Armengol M (2020) Management of morbidly obese patients during the outbreak of new coronavirus pandemic: commentary and recommendations from a specialist center in Spain. Bariatric Surg Pract Patient Care 15:110-113. https://doi. org $/ 10.1089 /$ bari.2020.0032

5. Arteaga-González IJ, Martín-Malagón AI, Ruiz de Adana JC, de la Cruz Vigo F, Torres-García AJ, Carrillo-Pallares AC (2018) Bariatric surgery waiting lists in Spain. Obes Surg 28:3992-3996. https://doi.org/10.1007/s11695-018-3453-Z

6. Christou NV, Efthimiou E (2009) Bariatric surgery waiting times in Canada. Can J Surg 52:229-234

7. Padwal RS, Majumdar SR, Klarenbach S, Birch DW, Karmali S, McCargar L et al (2012) Health status, quality of life, and satisfaction of patients awaiting multidisciplinary bariatric care. BMC Health Serv Res 12:139. https://doi.org/10.1186/1472-6963-12139

8. Kolotkin RL, Andersen JR (2017) A systematic review of reviews: exploring the relationship between obesity, weight loss and healthrelated quality of life. Clin Obes 7:273-289. https://doi.org/10. 1111/cob.12203

9. Taylor VH, Forhan M, Vigod SN, McIntyre RS, Morrison KM (2013) The impact of obesity on quality of life. Best Pract Res Clin Endocrinol Metab 27:139-146. https://doi.org/10.1016/j. beem.2013.04.004

10. Daigle CR, Augustin T, Wilson R, Schulz K, Fathalizadeh A, Laktash A et al (2020) A structured approach for safely reintroducing bariatric surgery in a COVID-19 environment. Obes Surg. https://doi.org/10.1007/s11695-020-04733-8

11. Rubino F, Cohen R, Mingrone G, le Roux CW, Mechanick JI, Arterburn DE et al (2020) Bariatric and metabolic surgery during and after the COVID-19 pandemic: DSS recommendations for management of surgical candidates and postoperative patients and prioritisation of access to surgery. Lancet Diabetes Endocrinol 8587:1-9. https://doi.org/10.1016/S2213-8587(20)30157-1

12. Durand MA, Carpenter L, Dolan H, Bravo P, Mann M, Bunn F et al (2014) Do interventions designed to support shared decision- making reduce health inequalities? A systematic review and meta-analysis. PLoS One 9(4):e94670. https://doi.org/10.1371/journal.pone. 0094670

13. Stacey D, Légaré F, Lewis K, Mj B, Cl B, Kb E, et al. (2017) Decision aids for people facing health treatment or screening decisions (Review) Summary of findings for the main comparison. Cochrane Database Syst Rev 1-242. https://doi.org/10.1002/ 14651858.CD001431.pub5.www.cochranelibrary.com.

14. Rodriguez-Gutierrez R, Gionfriddo MR, Ospina NS, Maraka S, Tamhane S, Montori VM et al (2016) Shared decision making in endocrinology: present and future directions. Lancet Diabetes Endocrinol 4:706-716. https://doi.org/10.1016/S2213-8587(15) 00468-4

15. Elwyn G, Frosch D, Thomson R, Joseph-Williams N, Lloyd A, Kinnersley P et al (2012) Shared decision making: a model for clinical practice. J Gen Intern Med 27:1361-1367. https://doi.org/ 10.1007/s11606-012-2077-6
16. Casimiro Pérez JA, Fernández Quesada C, del Val Groba Marco M, Arteaga González I, Cruz Benavides F, Ponce J et al (2018) Obesity surgery score (OSS) for prioritization in the bariatric surgery waiting list: a need of public health systems and a literature review. Obes Surg 28:1175-1184. https://doi.org/10.1007/s11695-017-3107-6

17. Rabin R, de Charro F (2001) EQ-SD: a measure of health status from. Ann Med 33:337-343. https://doi.org/10.1111/j.1461-0248. 2011.01689.x

18. Herdman M, Badia X, Berra S (2001) El EuroQol-5D: una alternativa sencilla para la medición de la calidad de vida relacionada con la salud en atención primaria. Aten Primaria 28: 425-429. https://doi.org/10.1016/s0212-6567(01)70406-4

19. Sharma AM, Kushner RF (2009) A proposed clinical staging system for obesity. Int J Obes 33:289-295. https://doi.org/10.1038/ijo. 2009.2

20. Chiappetta S, Stier C, Squillante S, Theodoridou S, Weiner RA (2016) The importance of the Edmonton Obesity Staging System in predicting postoperative outcome and 30-day mortality after metabolic surgery. Surg Obes Relat Dis 12:1847-1855. https://doi.org/ 10.1016/j.soard.2016.02.042

21. Kuk JL, Ardern CI, Church TS, Sharma AM, Padwal R, Sui X et al (2011) Edmonton obesity staging system: Association with weight history and mortality risk. Appl Physiol Nutr Metab 36:570-576. https://doi.org/10.1139/h11-058

22. Padwal RS, Pajewski NM, Allison DB, Sharma AM (2011) Using the Edmonton obesity staging system to predict mortality in a population-representative cohort of people with overweight and obesity. Can Med Assoc J 183:E1059-E1066. https://doi.org/10. 1503/cmaj.110387

23. Skulsky SL, Dang JT, Battiston A, Switzer NJ, Birch DW, Sharma AM et al (2019) Higher Edmonton Obesity Staging System scores are associated with complications following laparoscopic Roux-enY gastric bypass. Surg Endosc 34:3102-3109. https://doi.org/10. 1007/s00464-019-07067-4

24. Aasheim ET, Aylwin SJB, Radhakrishnan ST, Sood AS, Jovanovic A, Olbers T et al (2011) Assessment of obesity beyond body mass index to determine benefit of treatment. Clin Obes 1:77-84. https:// doi.org/10.1111/j.1758-8111.2011.00017.x

25. Valderhaug TG, Aasheim ET, Sandbu R, Jakobsen GS, Småstuen MC, Hertel JK et al (2016) The association between severity of King's Obesity Staging Criteria scores and treatment choice in patients with morbid obesity: a retrospective cohort study. BMC Obes 3:1-7. https://doi.org/10.1186/s40608-016-0133-1

26. Almandoz JP, Xie L, Schellinger JN, Mathew MS, Gazda C, Ofori A et al (2020) Impact of COVID-19 stay-at-home orders on weightrelated behaviors among patients with obesity. Clin Obes 10(5): e12386. https://doi.org/10.1111/cob.12386

27. Walędziak M, Różańska-Walędziak A, Pędziwiatr M, Szeliga J, Proczko-Stepaniak M, Wysocki M et al (2020) Bariatric surgery during COVID-19 pandemic from patients' point of view - the results of a national survey. J Clin Med 9:1697. https://doi.org/10. 3390/jcm9061697

28. Moreno Gijón M, Díaz Vico T, Rodicio Miravalles JL, LópezNegrete Cueto E, Suárez Sánchez A, Amoza Pais S et al (2020) Prospective analysis regarding health-related quality of life (HRQOL) between morbid obese patients following bariatric surgery versus on a waiting list. Obes Surg. https://doi.org/10.1007/s11695020-04652-8

29. Messiah SE, Sacher PM, Yudkin J, Ofori A, Qureshi FG, Schneider B et al (2020) Application and effectiveness of eHealth strategies for metabolic and bariatric surgery patients: a systematic review. Dig Health 6:1-21. https://doi.org/10.1177/2055207619898987 
30. Wang CD, Rajaratnam T, Stall B, Hawa R, Sockalingam S (2019) Exploring the effects of telemedicine on bariatric surgery followup: a matched case control study. Obes Surg 29:2704-2706. https:// doi.org/10.1007/s11695-019-03930-4

31. Vilallonga R, Lecube A, Fort JM, Boleko MA, Hidalgo M, Armengol M (2013) Internet of things and bariatric surgery follow-up: comparative study of standard and IoT follow-up. Minim
Invasive Ther Allied Technol 22:304-311. https://doi.org/10.3109/ 13645706.2013.779282

Publisher's note Springer Nature remains neutral with regard to jurisdictional claims in published maps and institutional affiliations. 